\title{
Diplomatic identity and communication: using Q methodology to assess subjective perceptions of diplomatic practitioners
}

\author{
Steven L. Pike ${ }^{1}\left[\right.$. Dennis F. Kinsey ${ }^{1}$
}

Revised: 7 July 2021 / Accepted: 8 July 2021

(c) The Author(s), under exclusive licence to Springer Nature Limited 2021

\begin{abstract}
This paper initiates exploration of how self-perceptions of role and identity held by public diplomats may impact the practice of public diplomacy. It validates Q Methodology, a scientific method for the study of subjective perception, as a means of identifying, categorizing, and analyzing self-perceptions. Researchers surveyed American public diplomats regarding attributes that they ascribe to the role of diplomatic communicator, successfully identified and categorized such attributes, identified clusters of difference within the subject group, and correlated those differences to demographic factors. This paper focused on the results of one survey group. Future cross-sectional and longitudinal research will compare these perceptions to those of other groups, including across cultural and national boundaries.
\end{abstract}

Keywords Public diplomacy $\cdot$ Q Methodology $\cdot$ Diplomacy $\cdot$ Communication theory of identity $\cdot$ Identity and communication $\cdot$ International relations $\cdot$ Sociology of professions

\section{Introduction}

These are tough times for diplomats. The twenty-first century international system is in convulsion following the conclusion of the wars of the 20th, and the rules are up for debate and renegotiation. A wave of populism and nationalism has swept through the major and secondary powers in the system, breaking patterns founded on the maintenance of a rules-based international political and economic system by the United States and its western allies. Diplomats are buffeted by strange new winds and tides of history, while scholars of international relations and diplomatic studies have their hands full analyzing the impact of change on international relationships, foreign policies, and diplomatic institutions and practices.

These are tough times for communicators. Technology has reduced the world to a small, crowded, and extremely noisy neighborhood. Thirty years ago, contacting a friend overseas required a special air mail envelope and extra postage, or an egregiously expensive phone call; twenty years

Steven L. Pike

slpike@syr.edu

1 Department of Public Relations, S. I. Newhouse School of Public Communications, Syracuse University, Syracuse, NY 13244, USA ago, email; 5 years ago, text in real time; and in just 1 year, 2020, Covid-19 taught us all how to calculate time zones to put people in five different time zones on the same video call for the fractional marginal cost of an internet hookup. Technology has, more critically, smashed structures of authority and hierarchy in communication; a popular meme notes that over the past 20 years, claims of expert knowledge have devolved from 'noted scientists and experts vetted by journalists' to 'everyone on Facebook.' An infinite plethora of platforms, ease of access, balkanization of the public into communities polarized and walled-in by cognitive dissonance, and the ability of malign operators to undermine the definition of truth itself have left communicators fighting to get a word in edgewise in the howling storm.

The authors bring individual lifetimes of academic study and practical experience from both of these fields and believe that an interdisciplinary approach to the challenges facing both fields yields opportunity for fruitful research with both practical and pedagogical value. We choose to study public diplomats because they occupy a unique niche at the intersection of the two fields. Public diplomats are diplomats with a particular professional charge: communication with the publics of foreign nations to advocate views and policies, share cultural perspectives, increase mutual understanding, persuade foreign publics, and influence the decisions of foreign governments, leaders, and elites. As 
diplomats, they are subject to the forces and factors that influence the diplomatic profession; their specific responsibility as public communicators equally subjects them to the forces and factors influencing the field of mass communication. Both international relations and public diplomacy scholars are engaged in inquiry into the impact of changing communication technology on their respective fields, but recent public diplomacy scholarship has focused on networks, technology, institutions, and diplomatic practices (Melissen 2007; Gilboa 2008; Zaharna 2010; Pamment 2012; Manor 2019), not on taking the practitioner per se as the unit of analysis.

Second, we choose to study a particular attribute of these professionals: their self-perceptions as communication practitioners. There is substantial theory that connects self-perception and identity to communication (Hecht 1993; Hecht et al. 1993, 2003; Sofer 1997; Jung and Hecht 2004; Faizullaev 2006), and the authors agree that how communicators perceive their roles and define their personae greatly influences how they communicate with others. Sociology of professions theory holds that self-perception and identity are an essential part of the definition of a given profession and the values and mores that practitioners assimilate, follow, and pass on to others (Parson 1964; Millerson 1964; Brante 1988). We believe that perceptions of self-identity on the job provide a unique window into how public diplomacy practitioners both define and perform their profession. Little has been done on this particular track, and a formal sociology of the public diplomacy profession remains to be fully elaborated.

Finally, we hope to test and validate a specific methodological approach to the question. The authors propose to apply Q methodology (Stephenson 1953), a scientific method for the study of subjectivity (Stephenson 1953; Brown 1980). This methodology facilitates the effort to assess self-perception, discern how public diplomats perceive themselves as communicators, and contribute those insights to the elaboration of a sociology of public diplomacy. Future cross-sectional research would seek to identify drivers of differences between the self-perceptions of public diplomats of different nations and cultures, different generations, or between self-perceptions of practitioners and perceptions of diplomats held by the general public. Future longitudinal research would seek to identify drivers of change in self-perception over time, e.g., technological, political, social, or other factors.

\section{Literature review}

The interdisciplinary nature of this undertaking draws upon several strands of thought and four general propositions. In short, these are the questions that have brought us to the departure point for our research agenda.

\section{Public diplomats are communicators}

Some form of communication akin to diplomacy has existed for as long as humans have divided themselves, whether nationally, politically, tribally, religiously, or ethnically. Herodotus and Plato wrote of envoys sent to consult sacred Greek oracles, or to observe the world outside of the individual city state and return with reflections on the culture and behavior of others (Constantinu and Sharp 2016). General agreement exists that public diplomacy implies communicating the policies of an international actor to the citizens of foreign countries (Pamment 2012). Malone (1988) asserted outreach to foreign citizens as an avenue for one state to influence the behavior of another. Jowett and O'Donnell (2012) described public diplomacy as both government cultivation of another country's public and transnational interactions between private citizens and groups and intercultural exchange. Sevin (2015) expanded the roster of legitimate publics from states and state-sanctioned actors to non-state groups in other countries. Communication has lay at the heart of efforts to categorize public diplomacy practices (Gilboa 2000; Nye 2008; Cull 2008; Fitzpatrick 2010). Most recently, public diplomacy scholars have compared public diplomacy to modern and ethical practices of public relations (Fitzpatrick 2007, 2010; Fitzpatrick et al. 2013).

\section{Public diplomats are subject to forces of change that influence diplomacy and mass communication}

The predominant streams of current scholarly inquiry in public diplomacy focus on the impact of twentieth and twenty-first century technological change and democratization on the communications infrastructure that underlies public diplomacy, and we concur fully with the argument that political and technological change has wrought radical change on the profession.

Prior to this change, the principal role of diplomats to sustain communication among leaders and elites. Diplomats now bear the equal, and perhaps greater, responsibility to communicate directly with the citizens of foreign nations, cultivate their attention, and influence their political opinions. This process of engaging, persuading, and influencing a foreign public in order to advance one's own foreign policy goals lies at the heart of the practice of public diplomacy. Melissen (2007) and Melissen and Hocking (2015), 
in particular, chronicle the rise of a technology- and internet-driven "new public diplomacy" in the twenty-first century that requires practitioners to elevate dialog, exchange of information, and robust engagement of the media and foreign publics over monolog, one-way provision of information, distancing from the public, and narrow media advocacy. Moreover, Melissen argues that these changes in dialog in the sphere of public diplomacy reverberate into traditional diplomatic practices, requiring ordinary diplomats to adopt the tools of public diplomacy within and in parallel to their diplomatic dialogs. Other scholars concur with this expansion of impact. Gilboa (2008) argues that revolutionary changes in mass communication, politics, and international relations in the post-cold war world made reputation achieved through soft power (attraction and persuasion) more important than the territory, access, and raw materials traditionally acquired through hard power (military and economic tools). Nye (2008) agrees that international relations have changed from a contest over whose military or economy wins into a contest of competitive credibility, and that in a world with an increasing number of democratically governed states, states will find shaping foreign public opinion as important to success as traditional diplomatic dialog.

A focus on systems, states, and institutions has left a gap in the research, however. Study of public diplomacy has examined the nature of the practice, the activities that comprise it, various theories and their application, conceptual models for implementation, relationships to other disciplines, and the platforms, technology, and cultural elements that impact the field. Zaharna (2010), in her study of networked public diplomacy, explored the roles that connectivity, interaction, culture, image, and identity play in the age of internet-based communication. Manor (2019) studied the infusion of the culture of digital society into the culture, practices, and work patterns of diplomatic institutions. Less scholarship has focused on the practitioners themselves and the unique human element that the diplomat as an individual brings to the job. Taking the practitioner as the unit of analysis helps us to reveal and understand forces that condition, impact, and affect them as individual professionals and practitioners. This can help us develop a more robust understanding of the profession, elaborate a sociology of public relations, and support efforts to manage, train, and strengthen the public diplomacy function.

\section{Diplomacy is a profession, and its practitioners are, therefore, affected by questions of subjective self-perception.}

Our work also acknowledges affordances from the sociology of professions and may provide useful inquiry into the impact of subjective self-perception on the behavior of professionals in a hierarchy. We hope, moreover, to contribute meaningfully to nascent efforts to elaborate a sociology of the profession of public diplomacy. Diplomats worldwide perceive themselves and are perceived by others, to be members of a profession. They belong to organizations in which generalized values temper complexity and ensure conformity as complex hierarchies evolve and differentiate (Parson 1964). They possess the key attributes of a profession: skills; education and training; competence; codes of conduct; a sense of common identity, service, and higher purpose; and systems of examination and recruitment that perpetuate the values of the profession (Millerson 1964). They assert that their profession is more difficult, more dangerous, more demanding of special skills and knowledge, and deserves higher compensation and prestige (Brante 1988). They are, moreover, not solely organizations devoted to the altruistic performance of good in society, but self-interested social organizations that use the attributes that define them as a profession to insulate and protect themselves from change and external influence (Brante 1988).

This is also a new and unexplored angle within this discipline. Some scholars have explored the influence of government on private sector professions (Bourgeault 2006; Lewis 2006; Ackroyd and Muzio 2007; Suddaby et al. 2007; Currie et al. 2009; Muzio and Kirkpatrick 2011), but these explorations have been limited to the impacts of government efforts to impose regulation.

For our purposes, one additional conclusion is warranted: the reliance on perception as a key element in the analysis advocates the use of a methodology that accounts for subjectivity.

\section{Communication is also intrinsically linked to subjective self-perceptions of identity}

The place of identity, self-image, and adoption of roles in communication is long established. Sofer (1997), comparing the diplomat to Albert Camus' stranger, portrays diplomats as drastically — even brutally - sacrificing individual self to a professional persona and agency to the state represented. The diplomat must not only cultivate and maintain a certain degree of estrangement in his or her outward relations but must carry the masquerade through to his or her own emotions. This process may be so intense and thorough as to engender a transformation sufficiently profound to displace the diplomat's sense of self and invite crises of identity (pp. 182-3). Sofer even makes the drastic assertion that the resolution of such a crisis must not be preserving the self, but the elimination of self for the sake of objective presentation" (emphasis added) (p. 184).

Faizullaev (2006) provides a more nuanced and balanced view. He concurs that the diplomat assumes the persona of his or her state in the perceptions of the foreign 
audience, representing the "personhood and selfhood of the home country" as the "face and soul" of that country. (p. 501). Manor (2019) description of national "selfies" (vesting nation states with online personae that have the characteristics of an individual) parallels this phenomenon in the digital communication age. Faizullaev (2006) further agrees that the diplomat disassociates mission from self, that there is potential for the loss of self, and that the process is linked to successful execution of the diplomatic. He rejects, however, complete abnegation of the self as neither possible nor desirable. As he writes, "a hidden but highly significant component of the entire system of diplomacy is the self of the diplomat," but "[D]iplomats are not merely small cogs in a foreign policy machine. They possess emotions, temperament, character, dispositions, prejudices, and other attributes of a human being" (p. 498). Faizullaev (2016) argues that the outcome is not elimination of the self in favor of the professional persona but a balanced integration of the personal and professional identities of the practitioner.

Finding that balanced integration, however, requires a schema for organizing and categorizing perceived identity that impacts communication, and the Communication Theory of Identity (Hecht 1993; Hecht et al. 1993, 2003; Jung and Hecht 2004) provides a robust one. It explores the relationship and mutual influences between identity and communication. Hecht et al., frame identity and communication as a single, inseparable activity- -identity is communication"- that act upon each other. Communication is founded inexorably on personal identity, in that one speaks from one's own knowledge, perceptions, and definition of who one is. Communication also, however, is equally impacted by interactions of different facets of identity at multiple levels. The theory posits four interlocking layers, or frames, of identity:

- Personal, involving the individual's self-concepts and self-image;

- Enacted, meaning the individual's performed or expressed identity, i.e., social behaviors that may be adopted to demonstrate the individual's role, status, or affiliation;

- Relational, meaning roles that the individual undertakes and "co-creates" in relationships and social interactions with others. Relational identity exists on three subordinate levels:

o perceptions of how one is seen by others (also referred to as ascribed relational identity);

o a sense of self obtained through relationships, i.e., the identity a person possesses as someone's friend, spouse, or parent; identities that arise from relationships themselves, e.g., siblings or a married couple;

- Communal, meaning identities that are ascribed by society to groups or collectivities based on a wide variety of generalized characteristics, e.g., doctors, lawyers, parents, politicians, students, women, men, members of demographic groups, Christians, Muslims, LGBTQ, etc. (Hecht 1993; Hecht et al. 1993, 2003; Jung and Hecht 2004).

This robust schema grounds the assertion that an interplay of perceived identities drives the choices of actions and behavior that professionals might make. The reliance on perception, again, reinforces the need for a methodology that accounts for subjectivity.

\section{Performance of a profession is also linked to subjective management of factors}

The role that identity and identity perceptions in communication, both in general and specifically with regard to diplomatic communication, is clear. One additional consideration creates significant implications for the study of diplomatic identity as a factor in communication and leads to a key observation on the subjectivity of diplomatic identity: it is an amalgam of internally and externally imposed factors and attributes, processed through the cognition of the individual practitioner. When a diplomat acts like a diplomat, he or she is not simply "following the manual," but his or her interpretation of the manual. We cannot fully understand the impact of diplomatic identity on communication simply by examining some objective reality of what a diplomat is; we must understand the subjective interpretation of what a diplomat believes a diplomat ought to be as they undertake the act of communication. Once again, we are drawn to the observation that a thorough exploration of the research questions requires a methodology that allows us to test for, measure, and include aspects of subjectivity.

\section{Research questions and hypotheses}

Our inquiry commences with a series of three research questions and three hypotheses:

R1. What are the elements of identity most closely associated with the "persona" of a public diplomacy practitioner?

$\mathrm{R} 2$. Are these elements shared by all practitioners, or are there variations? If so, what is the nature of these variations, how are they manifested or expressed, and what causes them? 
R3. Does Q Methodology offer a valid method for identifying, categorizing, and comparing elements, and for discerning drivers of difference among different groups?

H1. There is a shared persona composed of attributes broadly shared by practitioners of public diplomacy.

H2. Differences over attributes can be identified, explained, and managed within the bounds of the profession.

H3. Q Methodology can help us identify and categorize subjective perceptions in a meaningful and valid manner, and thereby draw conclusions about differences in perception among members of a group, or between members of different groups.

In order to pursue these questions, we have chosen a methodology that investigates subjective perceptions by a population. This will, of necessity, be a long-term effort with many steps. The first phase, presented here, involves the testing of that methodology and the development of baseline survey information on demographics essential to answering the longer-term questions.

\section{Methodology}

The researchers chose Q methodology (Stephenson 1953), a scientific method for the study of subjectivity (Stephenson 1953; Brown 1980). Q methodology begins with the development of a concourse of communication, or a concourse, defined as a robust body of cognition about an issue that may include everything and anything that is known, believed, felt, or opined about a subject (Stephenson 1978; Stephenson 1980; McKeown and Thomas 2013). A Q researcher develops from the concourse a $Q$ sample, a limited collection of specific statements, attributes, or characteristics that broadly and faithfully represent the concourse (Stephenson 1953; Brown 1980). The Q sample is presented to participants in a $Q$ study, which asks each participant to create a $Q$ sort: a distribution of the elements of the $\mathrm{Q}$ sample into a grid according to a condition of instruction, generally that the elements in the $\mathrm{Q}$ sample are "most representative" and "most unrepresentative" of the subject of the investigation. Spaces on the grid are arranged in the form of a flattened inverted bell curve, as shown in Fig. 1.

Responses at the midpoint of the spectrum, i.e., that provoke indifferent reactions among participants, are assigned

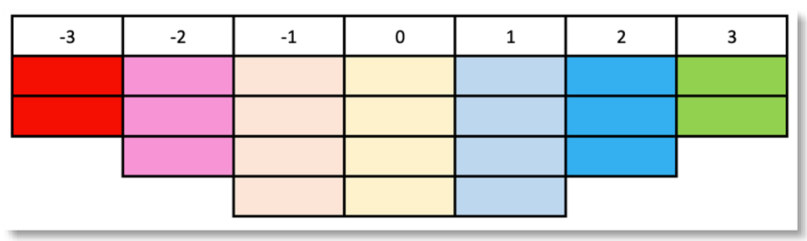

Fig. 1 Q sort response grid a value of zero. Relatively more representative responses are assigned increasingly positive values, e.g., $+1 .+2,+3$, etc.; relatively more unrepresentative responses are assigned increasingly negative values, e.g., $-1,-2,-3$, etc.

Each respondent's $\mathrm{Q}$ sort represents a unique arrangement of the statements in a $Q$ sample. $Q$ enables researchers to compare $\mathrm{Q}$ sorts mathematically, weight responses, and identify groups of respondents whose $\mathrm{Q}$ sorts are similar in statistically significant ways. Researchers can then synthesize Q sorts that are weighted representations of the perspectives of a group of respondents within the full sample. Respondents who show similar sorting patterns are described as loading on factors: subjective perceptions shared by the members of a group. During the initial analysis, these as-yet-undetermined factors (and their groups) are referred to by letters (factor A, factor B, factor C, etc.). Q asserts that these factors may be discerned by further analysis. Q does so through a form of "inverted factor analysis," taking the person as the unit of analysis and analyzing people with similar subjective perceptions to understand the factors driving those similarities. Each group is analyzed internally to itself and then in comparison to other groups of respondents to derive conclusions and observations.

The Q sample for this study was derived from various sources, academic and professional, to capture a broadly representative spectrum of perspectives. Researchers reviewed the initial 100 items to produce a final Q sample of 45 terms, shown in Table 1 below.

The $\mathrm{Q}$ study was administered to a group of American diplomats, largely—though not exclusively-public diplomacy practitioners, between September 14 and 31, 2019. Researchers posted requests in social media groups (e.g., Facebook) frequented by diplomats. Respondents were

Table 1 Q sample

\begin{tabular}{|c|c|c|c|c|c|}
\hline 1 & Pragmatic & 16 & Artificial & 31 & Protocol conscious \\
\hline 2 & Confident & 17 & Principled & 32 & Analytical \\
\hline 3 & Calculating & 18 & Political & 33 & Reasoned \\
\hline 4 & Passionate & 19 & Skilled writer & 34 & Observer \\
\hline 5 & Unemotional & 20 & Eloquent & 35 & Reporter \\
\hline 6 & Detached & 21 & Equivocating & 36 & Expert \\
\hline 7 & $\begin{array}{l}\text { Relationship } \\
\text { builder }\end{array}$ & 22 & Detail oriented & 37 & Cultural explorer \\
\hline 8 & Transactional & 23 & Visionary & 38 & Avid learner \\
\hline 9 & Argumentative & 24 & Courageous & 39 & Educated \\
\hline 10 & Likeble & 25 & Risk-averse & 40 & Leader \\
\hline 11 & Loyal & 26 & Resilient & 41 & Manager \\
\hline 12 & Representative & 27 & Chameleon & 42 & Negotiator \\
\hline 13 & Service oriented & 28 & Privileged & 43 & Problem solver \\
\hline 14 & Mission oriented & 29 & Noble & 44 & Self-aware \\
\hline 15 & Truth teller & 30 & Ambitious & 45 & Out-of-touch \\
\hline
\end{tabular}


directed to a web-based application (VQMethod, n.d.) that presented the Q sample and asked them to sort the terms into a grid ranging from +4 to -4 according to the condition of

Table 2 Rotated factor loadings

\begin{tabular}{|c|c|c|c|c|c|}
\hline \multirow{2}{*}{$\begin{array}{l}\text { Participant } \\
\#\end{array}$} & \multicolumn{2}{|c|}{ Factor loadings } & \multirow{2}{*}{$\begin{array}{l}\text { Participant } \\
\#\end{array}$} & \multicolumn{2}{|c|}{ Factor loadings } \\
\hline & Factor A & Factor B & & Factor A & Factor B \\
\hline 1 & 0.5687 & 0.4462 & 20 & 0.7104 & -0.1236 \\
\hline 2 & 0.8031 & 0.1854 & 21 & 0.3775 & 0.3877 \\
\hline 3 & 0.3294 & 0.5158 & 22 & 0.7109 & 0.3577 \\
\hline 4 & 0.1838 & 0.3527 & 23 & 0.5060 & 0.5763 \\
\hline 5 & 0.5640 & 0.3062 & 24 & 0.3989 & 0.2932 \\
\hline 6 & 0.1973 & 0.7498 & 25 & 0.7316 & 0.2265 \\
\hline 7 & 0.4986 & 0.6189 & 26 & 0.5623 & 0.4572 \\
\hline 8 & 0.1215 & 0.7023 & 27 & -0.1923 & 0.3919 \\
\hline 9 & 0.7219 & 0.0841 & 28 & 0.4059 & 0.5994 \\
\hline 10 & 0.6141 & 0.3897 & 29 & 0.4135 & 0.5940 \\
\hline 11 & 0.4592 & 0.4479 & 30 & 0.6745 & 0.0825 \\
\hline 12 & 0.1231 & 0.5748 & 31 & 0.7951 & 0.1308 \\
\hline 13 & 0.7435 & 0.2104 & 32 & 0.7056 & 0.2237 \\
\hline 14 & 0.2447 & 0.4565 & 33 & 0.7612 & 0.1944 \\
\hline 15 & 0.7868 & 0.4218 & 34 & 0.8546 & 0.2198 \\
\hline 16 & -0.0436 & 0.5075 & 35 & 0.2491 & 0.6125 \\
\hline 17 & 0.4394 & 0.2421 & 36 & 0.8245 & 0.1368 \\
\hline 18 & 0.6878 & 0.1311 & 37 & 0.8239 & -0.0406 \\
\hline 19 & 0.4812 & 0.3896 & & & \\
\hline
\end{tabular}

Value 0.3225 or greater indicate significant factor loading at $p \leq 0.01$ instruction most like or most unlike a diplomat. Thirty-seven individuals responded to the survey.

Participants additionally were asked for open-ended reflections, in their own words, on the six terms sorted into the most extreme categories (i.e., +4 and -4 ), and a series of demographic questions designed to facilitate comparisons among groups of respondents: age group; nationality; foreign service "cone" (the functional track of the officer, e.g., public diplomacy, political, economic, management, consular); diplomatic rank; length of service as a diplomat; whether they were still active, retired, or separated from the diplomatic service; and whether they had ever been assigned as a deputy chief or chief of mission.

The completed Q sorts were correlated and factor analyzed with PQMethod (2014), an online Q analysis software program. Correlations and eigenvalue results of the unrotated factor matrix demonstrated two significant grouping factors, with eigenvalues of 14.653 for factor $\mathrm{A}$ and 3.590 for factor B. Factors were rotated according to the varimax method. Rotated factor loadings are shown in Table 2. Seventeen participants purely loaded on Factor A, nine purely loaded on Factor B, ten participants confounded on both factors, and one participant loaded on neither factor.

Weighted synthesized Q sorts for factors A and B are displayed in Tables 3 and 4, respectively.

Table 3 Weighted synthesized Q sorts for participants loading on factor A (Group A)

\section{FACTOR A}

\begin{tabular}{|c|c|c|c|c|c|c|c|c|}
\hline-4 & -3 & -2 & -1 & $\mathbf{0}$ & 1 & 2 & 3 & 4 \\
\hline Argumentative & Transactional & Calculating & Self Aware & Confident & Eloquent & Analytical & $\begin{array}{l}\text { Mission } \\
\text { Oriented }\end{array}$ & $\begin{array}{l}\text { Cultural } \\
\text { Explorer }\end{array}$ \\
\hline Out of Touch & Detached & Privileged & Reporter & $\begin{array}{l}\text { Protocol } \\
\text { Conscious }\end{array}$ & Expert & Skilled Writer & Problem Solver & $\begin{array}{c}\text { Relationship } \\
\text { Builder }\end{array}$ \\
\hline \multirow[t]{5}{*}{ Artificial } & Equivocating & Noble & Risk Averse & Leader & Pragmatic & Educated & Principled & $\begin{array}{l}\text { Service } \\
\text { Oriented }\end{array}$ \\
\hline & Unemotional & Chameleon & Manager & Likeable & Courageous & Avid Learner & Negotiator & \\
\hline & & Political & Truth Teller & $\begin{array}{c}\text { Detail } \\
\text { Oriented }\end{array}$ & Reasoned & Resilient & & \\
\hline & & & Visionary & Loyal & Passionate & & & \\
\hline & & & Representative & Ambitious & Observer & & & \\
\hline
\end{tabular}


Table 4 Weighted synthesized Q sorts for participants loading on factor B (Group B)

\section{FACTOR B}

\begin{tabular}{|c|c|c|c|c|c|c|c|c|}
\hline-4 & -3 & -2 & -1 & $\mathbf{0}$ & 1 & 2 & 3 & 4 \\
\hline Self-Aware & Artificial & Political & Avid Learner & Resilient & Calculating & Reasoned & Negotiator & Educated \\
\hline Noble & Loyal & Leader & Out of Touch & Confident & Expert & Privileged & Observer & $\begin{array}{l}\text { Protocol } \\
\text { Conscious }\end{array}$ \\
\hline \multirow[t]{5}{*}{ Visionary } & Argumentative & Chameleon & Likeable & $\begin{array}{l}\text { Cultural } \\
\text { Explorer }\end{array}$ & Transactional & $\begin{array}{c}\text { Service } \\
\text { Oriented }\end{array}$ & Skilled Writer & Analytical \\
\hline & Courageous & Truth Teller & $\begin{array}{c}\text { Detail } \\
\text { Oriented }\end{array}$ & Problem Solver & Reporter & Pragmatic & $\begin{array}{l}\text { Relationship } \\
\text { Builder }\end{array}$ & \\
\hline & & Manager & Detached & Risk Averse & $\begin{array}{l}\text { Mission } \\
\text { Oriented }\end{array}$ & Representative & & \\
\hline & & & Unemotional & Principled & Ambitious & & & \\
\hline & & & Passionate & Eloquent & Equivocating & & & \\
\hline
\end{tabular}

\section{Discussion}

\section{Comparison of attributes}

One of the unique and appealing benefits of Q methodology is the ability to combine the attributes that each group considers most like and most unlike a diplomat (i.e., the attributes placed at the extremes of "most like" and "most unlike") to produce a coherent picture of those assessments. In this instance, we can produce four "personae" or "character sketches." One persona that Group A would consider most representative of a diplomat, another representing the persona that Group B would consider most representative of a diplomat, and two more persona that each group would consider most unrepresentative of a diplomat. Comparing and contrasting those personae provides useful insights into the holistic view of each group.

Group A's idealized diplomat is (or should be) a missionand service-oriented cultural explorer who builds relationships, negotiates skillfully with an eye to solving problems, and has a strong sense of principle.

Group B's idealized diplomat is (or should be) a welleducated, analytical individual who can respect protocol and observe and report events with skilled writing, and who maintains good skills in negotiating understandings and building relationships.

Group A's non-diplomat is detached, artificial, and unemotional; someone who argues with others rather than seeking to engage and build connections, and who moreover thwarts the trust needed to build connections through a tendency to be equivocating and transactional.

Group B's non-diplomat is a more complex and conflicted persona. Group B agrees with Group A that a non-diplomat is argumentative and artificial. However, Group B also believes that a diplomat does not indulge in being self-aware, noble, and visionary. When compared to Group B's idealized diplomat, there appeared to the researchers to be a nuanced distinction between focusing on the job and focusing on the self. Group B's non-diplomat seems less interested in using objective skills to accomplish the task and more interested in personal realization.

These personae flow from a comparative analysis of the placement of attributes in the grid. Groups A and B had significant areas of agreement. Both groups valued building relationships and negotiation skills, and agreed that less reflective attributes include being argumentative, artificial, and political. Neither group felt that confident is particularly relevant to the profession, agreed that being a chameleon and-worse-artificial reflects poorly on a diplomat, and felt that being likable is less important than other characteristics. This shared downgrading of likability supports both Sofer's (1997) and Faizullaev's (2006) arguments that professional identity can override personal identity. Diplomats may not need to obliterate the self and submerge themselves in the identity of their home country, but it appears that getting the job done ranks higher than concerns about whether interlocutors like them personally. 
However, the groups differ significantly on other important attributes. Attributes placed in the middle of the grid signal indifference or weak reactions; the attributes at the extremes of the grid-positive or negative-are the ones over which the participants have strong opinions and feelings. On the positive side, Group A rated cultural explorer, relationship builder, and service oriented as the three attributes most like a diplomat. Group B rated educated, analytical, and protocol conscious as the three attributes most like a diplomat. On the negative side, Group A rated argumentative, artificial, and out of touch as the attributes most unlike a diplomat. Group B rated noble, self-aware, and visionary as the attributes most unlike a diplomat. Those divergences clearly indicate that the two groups have significant differences in their perceptions of what makes a diplomat and also what does not.

\section{Demographics}

Researchers next analyzed the information collected via the demographic questions to see whether they might explain differences between Groups A and B. Indeed, there appeared to be significant differences because of age and time in service. In Group A, $75 \%$ of respondents were 46 or older, with $46-55$ as the largest single group. $23 \%$ of respondents were under 46. In Group B, only 55\% of participants were 46 or older, while $44 \%$ were under 46 . Even more significantly, $75 \%$ of Group A had 15 or more years of service, while $23 \%$ had less than 15 years of service. That proportion is completely reversed in Group B, where only 23\% had 15 or more years of service and $77 \%$ had less than 15 years.

These demographic aspects add an important dimension to the interpretation of the results of the Q sort. It appears that as diplomats become more established in their careers, their perception of the field and the skillset required changes. Both groups agree that building relationships and the ability to negotiate, to bring people together through persuasion, are part of the craft. One must inspire trust and credibility in order to succeed at those tasks, which makes it logical to see both groups advocate a degree of authenticity (the opposite of artificiality). It is, lastly, hard to imagine anything more undiplomatic than picking an argument. At that point, however, the groups diverge. Group B, with relatively less time in service, focuses on more concrete aspects of the profession: observing, writing, reporting, and respect for protocol. Group A, on the other hand, with relatively more time in service, has developed a greater tolerance for initiative and action. Instead of observing and reporting on situations, these officers seek engagement as problem solvers. Rather than stick largely to protocol, they may rely on internalized codes of principle as a yardstick for action.

Our inquiry began with the proposition, grounded in the Communications Theory of Identity that it was possible to identify attributes that define the "persona" of a public diplomacy practitioner and that such attributes are broadly shared by practitioners. The observation in our data that do indeed congregate around specific attributes, negative and positive, bears out the first hypothesis.

The pattern of divergence between less-seasoned and more-seasoned diplomats bears out the second hypothesis that divergences may exist even within a profession. We found it significant that the factor of time in service strongly explained the divergence between the two groups of diplomats. This is consistent with the concept from sociology of professions that professions and their practitioners evolve through training, education, and assimilation of members to a common culture. More direct analysis would be required to establish a causal link, but we believe it lends credibility to the assertion that divergences are known and managed within this given profession.

\section{Additional observations}

Researchers anticipated that differences of foreign service cone might engender different perspectives. As noted in the introduction, public diplomats serve at the intersection of two fields, diplomacy and mass communication, and the two roles-diplomat and communicator-are quite different. Political and economic officers who engage diplomatic contacts discreetly and public diplomats who openly engage the press and the general public logically ought to see those jobs differently, require different skills and attributes to do them, and cause the individuals to value different skills and attributes. One participant ("Participant C," for want of a better term) from the political cone loaded on neither factor A nor factor B and took a perspective that was an intriguing hybrid of perspectives from the two dominant groups. Participant $\mathrm{C}$ agreed with Group A that mission oriented and cultural explorer were highly representative of a diplomat, and with Group B that protocol conscious, observer, and educated were also representative of a diplomat. $\mathrm{C}$ also agreed with Group A that transactional and calculating were unrepresentative of a diplomat and with Group B that visionary and noble were unrepresentative of a diplomat. Of particular interest to the researchers, $\mathrm{C}$ uniquely placed risk averse in the highest category of most representative, while Groups A and B gave it considerably lower significance. C's idealized diplomat/non-diplomat pairing seems to balance aloofness with interference. The idealized diplomat is focused on mission and protocol, observes and remains a cultural explorer but avoids risk-including, perhaps, the risk of being too much involved. The non-diplomat has strong moral and ethical opinions (visionary, courageous, noble, principled) and appears motivated by gain (transactional, calculating). A proper diplomat in Participant C's world in many ways more closely resembles the isolated, 
solitary figure elaborated by Sofer (1997); someone who elevates external rules, sublimates internal motivations, and maintains personal distance from the job at hand. While Q Methodology recognizes and accepts the single-case example, researchers cannot declare this one incidence to be a pattern; the manifestation of the perspective, however, is intriguing and merits further exploration.

\section{Further directions}

The success of the method in identifying significant attributes and clusters of difference that could be correlated to demographic factors indicates that Q Methodology can have useful and valid input into this inquiry. Further research will test whether the methodology can be extended in a meaningful way among different subject groups. Additional Q studies (including their demographic components) would seek to compare participants by age/generation, functional specialty (cone) in the diplomatic profession, and political/national/ cultural attributes. Understanding how these factors influence the development of a professional self-identity among public diplomats would improve efforts to define the professional ethos, elaborate a sociology of the profession that accounted for those factors, and ultimately produce better tools for recruiting, training, and managing public diplomacy expertise, and giving practitioners the best tools for excellent performance. Interviews and focus groups with non-anonymous participants would go beyond reflections on attributes deemed most representative or most unrepresentative to explore why participants rated attributes highly (or not) and confirm their holistic interpretations. Singlecase studies (McKeown and Thomas 2013; Rhoads 2017) may yield further insight into specific connections between experience and perceptions.

\section{Generational aspects}

Time in service and age appear to have played a significant role in differentiating participant opinion among diplomats. This observation has significant implications for the development of a sociology of the public diplomacy profession. The theory of the sociology of professions would expect time in service, the accumulation of experience in a career path, and assimilation of the principles of a profession to produce a dynamic evolution in the perspective of professionals. Exogenous cultural values, however, could produce a static difference in the perspectives of one generation of officers vis-à-vis another. Additional research is needed to clarify whether and to what degree the observed difference in the self-image of generational cohorts is static or dynamic.

\section{Functional aspects within the profession}

Specialty in the foreign service (represented in the American foreign service by “cone," e.g., public diplomacy, political, consular, etc.) did not appear to be the most significant factor in differentiating participant opinion. The results obtained from the single non-public diplomacy coned participant may be a personal variation, but further research into the distinctions between officers of different cones might help clarify the impact of foreign service cone on perceptions of diplomatic roles and identity. Whatever differences of perspectives public diplomats may have among themselves, there are clearly still other perspectives on the nature of the profession. Understanding how public diplomats perceive their identity not just per se, but in comparison and contrast to their own diplomatic colleagues, helps strengthen the elaboration of a sociology for the profession as a whole. Repeating the study with additional participants and participants from different practitioner cones, pursuing a single-case-study approach, or conducting in-depth interviews could reveal meaningful differences in perception between public diplomacy officers and colleagues of other cones.

\section{Political, national, and cultural aspects}

The initial round of research focused on American diplomats and sought to reveal differences of perception that might be tied to functional specialty (cone), generation, or length of service. It is the goal of the researchers to extend subsequent rounds to (a) Americans who are not diplomats, to explore whether a gap exists between a population of diplomats and their own citizens, and what implications that gap has for the profession as a profession; (b) non-American practitioners, allowing important comparisons across national and cultural boundaries of the subjective elements that impact communication and practice by diplomats in different countries. This would facilitate elaboration of common and divergent factors that can impact diplomatic communication, be they professional, cultural, or national/political.

\section{References}

Ackroyd, S., and D. Muzio. 2007. The reconstructed professional firm: Explaining changes in English legal practices. Organization Studies 28 (5): 729-747.

Bourgeault, I. 2006. Push! The Struggle for Midwifery in Ontario. Montreal, Québec: McGill-Queens University Press.

Brante, T. 1988. Sociological approaches to the professions. Acta Sociologica 31 (2): 119-142.

Brown, S.R. 1980. Political Subjectivity: Applications of Q Methodology in Political Science. New Haven, CT: Yale University Press.

Constantinu, C. M., \& Sharp, P. 2016. Theoretical perspectives in diplomacy. In P. K. Costas M. Constantinu (Ed.), The SAGE Handbook of Diplomacy (pp. 13-27). London, UK: Sage. 
Cull, N. 2008. Public diplomacy: Taxonomies and histories. Annals of the American Academy of Political and Social Science 616: $31-54$.

Currie, G., R. Finn, and G. Martin. 2009. Professional competition and modernizing the clinical workforce in the NHS. Work, Employment and Society 23 (2): 267-284.

Faizullaev, A. 2006. Diplomacy and self. Diplomacy and Statecraft 17 (3): 497-522.

Fitzpatrick, K. 2007. Advancing the new public diplomacy: A public relations perspective. Hague Journal of Diplomacy 2 (3): 187-211.

Fitzpatrick, K. 2010. The future of U.S. public diplomacy: An uncertain fate. Leidon: Martinus Nijhoff/Brill.

Fitzpatrick, K., Fullerton, J., \& Kendrick, A. 2013. Public relations and public diplomacy: Conceptual and practical connections. Public Relations Journal, 7(4), 1-21.

Gilboa, E. 2000, August. Mass communication and diplomacy: A theoretical framework. Journal of Communication Theory, 10(3), 275-309.

Gilboa, E. 2008. Searching for a theory of public diplomacy. Annals of the American Academy of Political and Social Sciences 616: $55-77$.

Hecht, M. 1993. A research odyssey: Towards the development of a Communication Theory of Identity. Communication Monographs 60: 76-82.

Hecht, M., Collier, M., \& Ribeau, S. 1993. African American Communication: Ethnic Identity and Cultural Interpretation. Thousand Oaks, CA: SAGE.

Hecht, M., R. Jackson, and S. Ribeau. 2003. African American communication: Exploring identity and culture. Mahwah, NJ, USA: Erlbaum.

Jowett, G., and V. O'Donnell. 2012. Propaganda and Persuasion. 5th Edition. Thousand Oaks, CA: Sage.

Jung, E., \& Hecht, M. 2004. Elaborating the Communication Theory of Identity: Identity Gaps and Communication Outcomes. Communication Quarterly, 52(3), 265-283

Lewis, J. 2006. Being around and knowing the players: Networks of influence in health policy. Social Science and Medicine 62 (9): 2125-2136.

Malone, G. 1988. Political advocacy and cultural communication Rhetoric and Political Discourse Series 11:

Manor, I. 2019. The Digitalization of Public Diplomacy. Palgrave Macmillan.

McKeown, B., \& Thomas, D. B. 2013. Q Methodology. Sage University Paper Series on Quantitative Applications in the Social Sciences, 07(66), 2nd ed. London: Sage.

Melissen, J. 2007. The New Public Diplomacy. UK: Palgrave Macmillan.

Melissen, J., and B. Hocking. 2015. Diplomacy in the Digital Age. The Hague: Netherlands Institute of International Relations Clingendael.
Millerson, G. 1964. The Qualifying Association. London, UK: Routledge \& Kegan Paul.

Muzio, D., and I. Kirkpatrick. 2011. Professions and organizations-a conceptual framework. Current Sociology 59 (4): 389-405.

Nye, J.S. 2008. Public diplomacy and soft power. Annals of the American Academy of Political and Social Science 616: 94-108.

Pamment, J. 2012. New Public Diplomacy in the 21st Century. London, UK: Routledge.

PQMethod. 2014. PQMethod.com. (P. Schmolck, Editor) Retrieved September 2019, from http://schmolck.org/qmethod/

Rhoads, James C. 2017. Foreword to the Special Issue: Q Methodology and the Single Case. Operant Subjectivity, 39(1), 1

Sevin, E. 2015. Pathways of connection: An analytial approach to the impacts of public diplomacy. Public Relations Review 41 (4): $562-568$.

Sofer, S. 1997. The Diplomat as Stranger. Diplomacy \& Statecraft 8 (3): 179-186.

Stephenson, W. 1953. The Study of Behavior: Q-Technique and Its Methodology. Chicago, IL, USA: University of Chicago Press.

Suddaby, R., D. Cooper, and R. Greenwood. 2007. Transnational regulation of professional services: Governance dynamics of field level organizational change. Accounting, Organizations, and Society 32: 333-362.

VQMethod. (n.d.). VQMethod.com. Retrieved September 2019, from http://www.vqmethod.com

Zaharna, R.S. 2010. Battles to Bridges: U.S. Strategic Communication and Public Diplomacy after 9/11. London, UK: Palgrave Macmillan.

Publisher's Note Springer Nature remains neutral with regard to jurisdictional claims in published maps and institutional affiliations.

Steven L. Pike , Department of Public Relations, S. I. Newhouse School of Public Communications, Syracuse University, Syracuse, N.Y., United States. Assistant Professor of Public Relations and Public Diplomacy, former diplomat and public diplomacy practitioner, specialist in international relations, public and media affairs, cultural and educational programming.

Dennis F. Kinsey , Department of Public Relations, S. I. Newhouse School of Public Communications, Syracuse University, Syracuse, N.Y., United States. Professor of Public Relations, Director Doctoral Program and Public Diplomacy Program. 